\title{
Quantitative trait loci for root lesion nematode (Pratylenchus thornei) resistance in Middle-Eastern landraces and their potential for introgression into Australian bread wheat
}

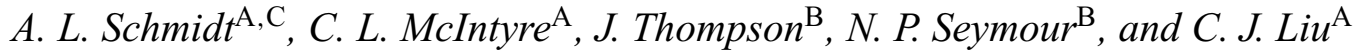

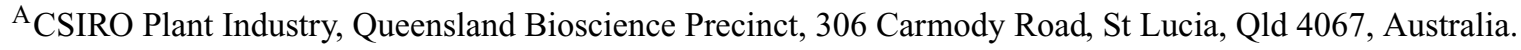 \\ ${ }^{B}$ Queensland Department of Primary Industries and Fisheries, Leslie Research Centre, PO Box 2282, Toowoomba, \\ Qld 4350, Australia. \\ ${ }^{\mathrm{C}}$ Corresponding author. Email: Adele.Schmidt@csiro.au
}

\begin{abstract}
Plant parasitic nematodes are a major biotic cause of wheat yield loss in temperate wheat-growing regions. Previous studies using Australian germplasm and/or synthetic hexaploid lines have identified quantitative trait loci (QTLs) for root lesion nematode resistance on chromosomes 2B, 6D, and 7A. This study examines Pratylenchus thornei resistance in 2 Middle-Eastern landraces (AUS13124 and AUS4926), using doubled haploid populations generated by crossing with the susceptible Australian cultivar Janz. Single marker regression and QTL analysis identified resistance loci on chromosomes 2B, 3B, 6D, and 7A, and a susceptibility locus on chromosome 1B. The 2B and 6D loci, which have been reported to explain up to $19 \%$ and $24 \%$ of variation, respectively, in previous studies, made smaller contributions in the Middle-Eastern varieties, explaining 2-13\% (2B) and 1-6\% (6D) of phenotypic variation in these populations. The previously reported 7A locus (P. neglectus resistance) was detected through single marker regression only (AUS13124 $\times$ Janz - LRS $=4.1, P=0.04292$; AUS4926 $\times$ Janz - LRS $=9.6, P=0.00195$ ), with genotype at the microsatellite marker Xgwm350.3 accounting for $3-23 \%$ of phenotypic variation. The previously unreported resistance QTL, located on chromosome 3B, explained up to $24 \%$ of phenotypic variation, and the susceptibility locus on chromosome $1 \mathrm{~B}$ explained up to $21 \%$. The $3 \mathrm{~B}$ locus was detected in both the AUS13124 $\times$ Janz (max. LRS $=20.13)$ and AUS4926 $\times$ Janz (max. LRS $=11.19)$ populations, and the 1B locus was detected in the AUS4926 $\times$ Janz population (max. LRS $=18.82$ ) only.
\end{abstract}

Additional keyword: QTL.

\section{Introduction}

Plant parasitic nematodes are a major biotic cause of yield loss in the world's temperate wheat-growing regions (Jung and Wyss 1999). In the northern wheat-growing region of Australia, the root lesion nematodes Pratylenchus neglectus and $P$. thornei cause substantial yield losses of wheat, with losses from $P$. thornei alone estimated as up to $80 \%$ in susceptible varieties (Thompson 1990; Vanstone et al. 1998). Previous studies have demonstrated that use of nematicides is neither effective, nor economically viable as a longterm management strategy, and can also have a significant negative effect on the growing environment (Taylor et al. 1999). It has therefore been suggested that the most promising long-term management option is development of resistant cultivars (Taylor et al. 1999; Thompson et al. 1999; Williams et al. 2002).

As biological assays for root lesion nematode (RLN) resistance are laborious and time-consuming (Barloy et al. 2000; Williams et al. 2002), more easily implemented methods of resistance screening are highly desirable. Use of molecular markers can potentially eliminate the need for large-scale phenotyping and allow rapid, efficient identification of resistance loci, facilitating development of new resistant varieties. Zwart et al. (2004a) have previously demonstrated that resistance to $P$. thornei in wheat is a polygenic, additive trait and as such, is a suitable target for marker-assisted selection programs.

Previous marker studies have resulted in the identification of several wheat loci conferring resistance to parasitic nematodes such as the cereal cyst nematode (CCN) (Heterodera avenae) (Dundas et al. 2001; Williams et al. 2002) and the cereal root-knot nematode (Meloidogyne nasi) (Barloy et al. 2000), but early indications suggest that these loci do not also confer resistance to Pratylenchus species (Nombela and Romero 2001).

In an investigation of $P$. neglectus resistance in Australian cultivars, Williams etal. (2002) identified a major resistance locus, Rlnn1, located on chromosome 7A. 
Zwart et al. (2005, 2006) have recently identified additional $P$. thornei and/or $P$. neglectus resistance quantitative trait loci (QTLs) on chromosomes $2 \mathrm{~B}$ and $6 \mathrm{D}$ (designated QRlnn.lrc-2B.1/QRlnt.lrc-2B.1 and QRlnn.lrc6D.1/QRlnt.lrc-6D.1, respectively), using populations derived from synthetic wheat lines crossed with Australian and Mexican breeding stocks. In this study, we examine P. thornei resistance in 2 Middle-Eastern landraces (AUS13124 syn. Morocco 426 and AUS4926 syn. Iraq 43) that have shown resistance to Pratylenchus species in prior studies (Seymour and Thompson 2001), using doubled haploid populations generated by crossing each of these landraces with the susceptible Australian cultivar Janz, with the aim of identifying novel resistance loci that can be introgressed into Australian germplasm using marker-assisted selection.

\section{Materials and methods}

Plant materials and nematode resistance screening

Seed for 2 doubled haploid (DH) populations was generated from $\mathrm{F}_{1}$ seed from crosses between the Middle-Eastern landraces AUS13124 and AUS4926 and the Australian cv. Janz (Seymour and Thompson 2001). To assay resistance in both the AUS13124 $\times \operatorname{Janz}(n=126)$ and AUS4926 $\times$ Janz $(n=126)$ populations, single plants were grown in 6 replicate experiments per population, arranged in randomised blocks in a glasshouse at the Queensland Department of Primary Industries Leslie Research Centre, Toowoomba, Qld $\left(27^{\circ} 33^{\prime} \mathrm{S}, 151^{\circ} 57^{\prime} \mathrm{E}\right)$, and inoculated using the procedures described in Thompson and Haak (1997) with the modifications of Zwart et al. (2004a). In addition to the $126 \mathrm{DH}$ progeny for each population, parental lines, uninoculated and unplanted pots, and 8 reference lines [Canary seed (Phalaris canariensis cv. Morocco), durum wheat cv. Yallaroi, and bread wheats GS50a, QT9048, QT8343, Cunningham, Gatcher, and Batavia] were also included in each replicate (total $n=136 \times 6$ replicates for each population).

Plants were grown from June to October 2001 and, after 16 weeks growth, plant tops were removed and the soil and roots extracted using the procedure of Zwart et al. (2004b, 2005, 2006), based on Whitehead and Hemming (1965). Numbers of $P$. thornei per $1 \mathrm{~mL}$ of extracted sample were counted in a Hawksley slide under a compound microscope and final results were expressed as number of nematodes per $\mathrm{kg}$ soil plus roots. These data were analysed by ANOVA using an $\ln (x+c)$ transformation, where $c$ is a constant chosen to best normalise the data, as per Proctor and Marks (1974) and Berry (1987) and these means were back-transformed to generate equivalent means. Following preliminary analysis of marker-trait associations using data from the 2001 trials, phenotyping was repeated in 2003 using the 20 most resistant and 20 most susceptible DH lines, plus the parental lines, uninoculated and unplanted pots, and 8 reference lines $(n=52 \times 6$ replicates for each population). Phenotypic datasets were assessed for correlation between 2001 and 2003, and tested for normality using the Kolmogorov-Smirnov test $(n>50)$ and/or the ShapiroWilks $(n<50)$ test, with a Lilliefors significance level using SPSS Version 11.0 for Windows.

\section{Marker genotyping}

Tissue samples for each of the lines, and the parental varieties, were collected during glasshouse trials, with DNA extracted by CTAB buffer (2\% CTAB, $100 \mathrm{~mm}$ Tris, $20 \mathrm{~mm}$ EDTA, $1.4 \mathrm{M} \mathrm{NaCl}, \mathrm{pH} 8.0$ ) lysis and deproteination via chloroform : isoamylalcohol purification, as per Schmidt et al. (2004). Aliquots of initial extractions were diluted in water to a final concentration of $\sim 25 \mathrm{ng} / \mu \mathrm{L}$ prior to polymerase chain reaction $(\mathrm{PCR})$.

Individual lines were genotyped using microsatellite markers initially developed by Röder et al. (1998), Pestsova et al. (2000), Varshney et al. (2000), Gupta et al. (2002), and Song et al. (2002), and amplified fragment length polymorphism (AFLP) markers generated using the AFLP Analysis System I and AFLP Starter Primers (Life Technologies/GIBCO BRL). The goal was to generate a framework map of each population consisting of 4-6 microsatellite markers per chromosome, with inter-marker spacing of $10-30 \mathrm{cM}$.

Amplification of microsatellite loci was performed in radio-labelled $7-\mu \mathrm{L}$ PCR reactions containing $1 \times$ PCR buffer (FisherBiotech International Ltd), $1.5 \mathrm{~mm} \mathrm{MgCl}_{2}, 0.2 \mathrm{~mm}$ lowC dNTPs (10 mM dATP, $10 \mathrm{~mm}$ dTTP, $10 \mathrm{~mm}$ dGTP, $1 \mathrm{~mm}$ dCTP), $9 \mu \mathrm{Ci}{ }^{33} \mathrm{P}-\mathrm{dCTP}, 0.2 \mu \mathrm{M}$ of each of the forwards and reverse primers (Röder et al. 1998; Pestsova et al. 2000; Varshney et al. 2000; Gupta et al. 2002; Song et al. 2002), 0.15 units of Tth Plus DNA polymerase (FisherBiotech International Ltd), and $25-50 \mathrm{ng}$ of genomic DNA. Thermocycle conditions were: $95^{\circ} \mathrm{C}$ for $1 \mathrm{~min} 15 \mathrm{~s}$, followed by 40 cycles of $95^{\circ} \mathrm{C}$ for $15 \mathrm{~s}$, annealing temperature $\left(\mathrm{T}_{\mathrm{a}}\right.$, primer dependent) for $15 \mathrm{~s}$, and $72^{\circ} \mathrm{C}$ for $30 \mathrm{~s}$. PCR was performed in a Perkin-Elmer GeneAmp 2700/9700 thermocycler.

Amplification of AFLP markers was achieved through EcoRI/MseI digestion of genomic DNA, ligation of adapters, and subsequent amplification of selected target fragments, following the procedures described by the manufacturer (GIBCO BRL/Life Technologies).

Visualisation of both microsatellite and AFLP products was achieved via electrophoresis through denaturing $5 \%$ polyacrylamide gels (6 $\mathrm{m}$ urea, $5 \%$ acrylamide : bisacrylamide $19: 1,1 \times \mathrm{TBE})$, and alleles were scored to 1 -bp accuracy with reference to a pUC18 sequence ladder.

\section{Marker-trait analysis}

Marker data were assembled into genetic maps and subjected to single marker analysis using MapManager QTXb20 software (Manly et al. 2001). Genetic maps and phenotypic data were then imported into QTL Cartographer for Windows Version 2.0 (Wang et al. 2004, Statistical Genetics, North Carolina State University, USA) for further analysis. Following $\chi^{2}$ testing to evaluate the extent of linkage disequilibrium, QTL detection was performed through composite interval mapping, using a stepwise regression model with a walk interval of $2 \mathrm{cM}$. Significance thresholds for QTLs were calculated for each set of phenotypic data by permutation (1000 permutations at $P<0.05$ and $P<0.10$ ) (Churchill and Doerge 1994). Where QTLs were detected, the proportion of phenotypic variation explained by each locus was estimated by the coefficient of determination $\left(R^{2}\right)$.

\section{Results}

\section{Nematode counts}

\section{AUS13124 × Janz}

In the 2001 phenotyping trials, the average nematode count (nematodes $/ \mathrm{kg}$ of soil, 6 replicates) for AUS13124 was 3337 (Fig. 1a). In 2003, the average nematode count for AUS13124 was 2980 (Fig. 1a). Average nematode counts for the susceptible cv. Janz were 27328 in 2001 and 5140 in 2003 (Fig. 1a). For those lines phenotyped in both 2001 and 2003, average counts in each year were significantly correlated $(r=0.779, P<0.0002, n=42)$. ANOVA of data in $2001(F=12.06,1$. s.d. $=1.0835, \mathrm{CV}=11.2, P<0.001)$ led to an $\ln (x+75)$ transformation. ANOVA of the 2003 dataset 


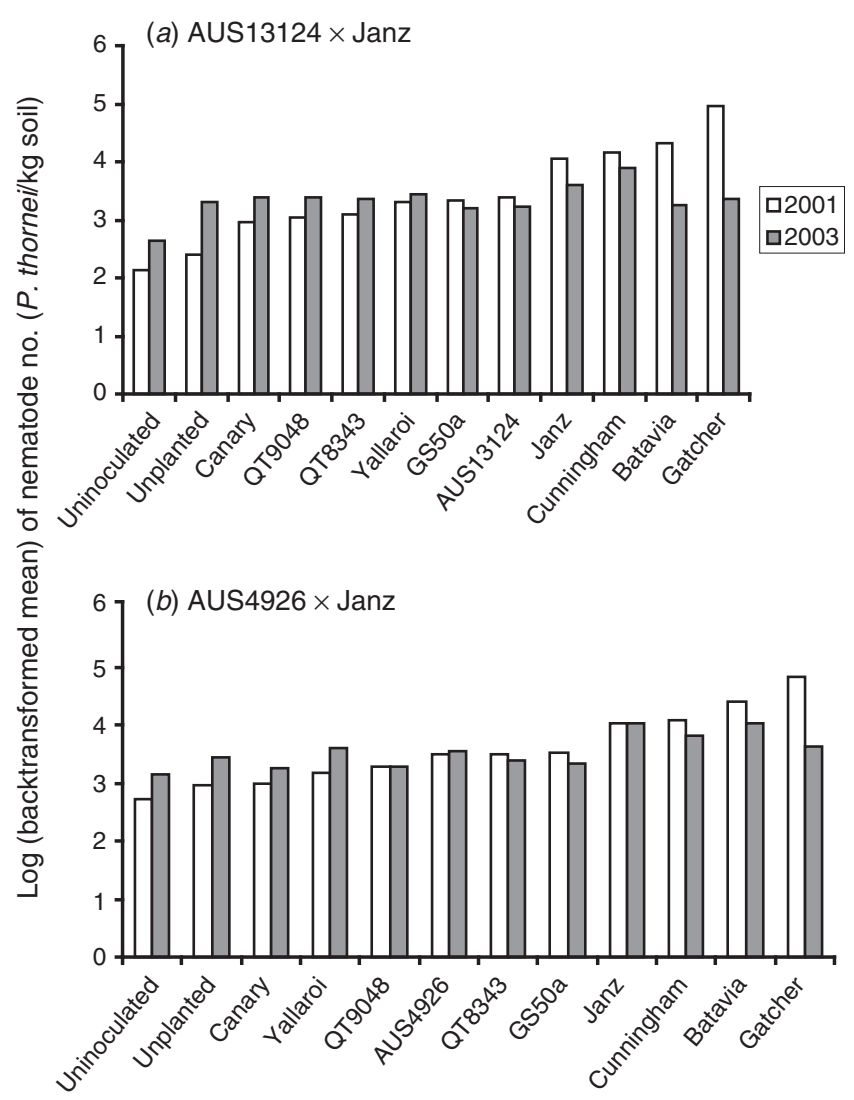

Fig. 1. Root lesion nematode (Pratylenchus thornei) counts for parental and control lines. $\log _{10}$ of back-transformed means are shown for parental and control lines in each year (6 replicates/population.year). Note that in 2001, all individuals in each population were phenotyped, but in 2003 only the 20 most resistant and 20 most susceptible lines (based on data from 2001) were phenotyped.

$(F=2.78$, 1.s.d. $=0.9799, \mathrm{CV}=10.4, P<0.001)$ led to an $\ln (x+700)$ transformation (Fig. 1a).

Back-transformed means were $\log _{10}$ transformed before QTL analysis. The transformation failed to generate a normal distribution in the 2001 dataset (KolmogorovSmirnov statistic $=0.138$, d.f. $=128, P<0.0001)$, but the 2003 dataset was normally distributed (ShapiroWilk statistic $=0.975$, d.f. $=42, P=0.200$ ). Skewness of the transformed datasets was $0.687 \pm 0.214$ in 2001, and $0.267 \pm 0.365$ in 2003. Kurtosis in the transformed dataset was $-0.590 \pm 0.425$ in 2001 and $-0.560 \pm 0.717$ in 2003 .

\section{AUS4926 × Janz}

In the 2001 phenotyping trials, the average nematode count (nematodes $/ \mathrm{kg}$ of soil, 6 replicates) for AUS4926 was 3432 (Fig. 1b). In 2003, the average nematode count for AUS4926 was 9078 (Fig. 1b). Average nematode counts for the susceptible cv. Janz were 16587 in 2001 and 12297 in 2003 (Fig. 1b). Nematode counts in 2001 were significantly correlated with nematode counts in 2003 $(r=0.814, P<0.0001, n=42)$. ANOVA of data in 2001 $(F=12.08,1 . s . d .=0.8768, \mathrm{CV}=8.9, P<0.001)$, led to an $\ln (x+400)$ transformation. ANOVA of the 2003 dataset $(F=4.04$, l.s.d. $=0.8790, \mathrm{CV}=9.5, P<0.001)$ led to an $\ln (x+350)$ transformation (Fig. 1b).

Nematode data for the AUS4926 $\times$ Janz population were $\log _{10}$ transformed before QTL analysis. The transformation failed to generate a normal distribution in the 2001 dataset (Kolmogorov-Smirnov statistic $=0.181$, d.f. $=128$, $P<0.0001$ ), but the 2003 dataset was normally distributed (Shapiro-Wilk statistic $=0.966, \quad$ d.f. $=42, \quad P=0.282$ ). Skewness of the transformed datasets was $0.901 \pm 0.216$ in 2001 , and $0.387 \pm 0.378$ in 2003. Kurtosis in the transformed dataset was $-0.394 \pm 0.428$ in 2001 and $-0.582 \pm 0.741$ in 2003 .

\section{Marker genotyping and genetic map construction}

\section{AUS13124 × Janz}

The AUS13124 $\times$ Janz population was genotyped at a total of 173 loci (15 AFLPs and 158 microsatellites). One hundred and fourteen of these markers were assembled into a framework map consisting of 18 linkage groups, spanning a total of $1987 \mathrm{cM}$, with an average intermarker spacing of $17 \mathrm{cM}$ (Fig. 2). Comparison with previously published maps (Röder et al. 1998; Harker et al. 2001) indicated that chromosomes $3 \mathrm{~A}, 5 \mathrm{~B}$, and $6 \mathrm{~A}$ were represented by unlinked markers only.

Chi-square tests revealed that 9 of the 114 mapped markers $(9 \%)$ showed significant $(P<0.05)$ distortion from the expected segregation ratio $(1: 1)$ : gwm156 $\left(\chi^{2}=8.82, n=109\right)$, gwm164.2 $\left(\chi^{2}=38.89, n=126\right)$, ACC/CTC. $1\left(\chi^{2}=6.95, n=121\right), \operatorname{gwm} 191.1\left(\chi^{2}=79.37\right.$, $n=126), \quad$ gwm60.1 $\left(\chi^{2}=51.58, \quad n=121\right), \quad$ gwm191.4 $\left(\chi^{2}=7.26, \quad n=124\right), \quad$ gwm340.1 $\left(\chi^{2}=14.79, n=125\right)$, gwm497.3 $\left(\chi^{2}=19.52, n=123\right)$, and $\operatorname{gdm} 132\left(\chi^{2}=11.56\right.$, $n=124)$.

\section{AUS4926 $\times$ Janz}

The AUS4926 $\times$ Janz population was genotyped at a total of 186 loci (29 AFLPs and 157 microsatellites). One hundred and forty-eight of these markers were assembled into a framework map consisting of 22 linkage groups, spanning a total of $3229.7 \mathrm{cM}$, with an average intermarker spacing of $22 \mathrm{cM}$ (Fig. 3). Comparison with previously published maps (Röder et al. 1998; Harker et al. 2001) indicated that all 21 wheat chromosomes were represented, along with an unidentified linkage group comprising AFLP markers only.

Chi-square tests revealed that 14 of the 148 mapped markers $(10 \%)$ showed significant $(P<0.05)$ distortion from the expected segregation ratio $(1: 1)$ : ACC/CTT.2 
$1 \mathrm{~A}$

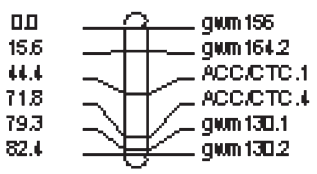

2A

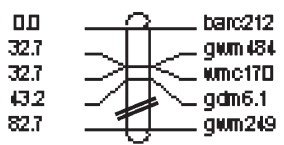

4A

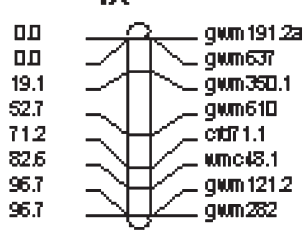

5 A

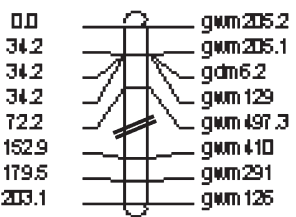

$1 \mathrm{~B}$

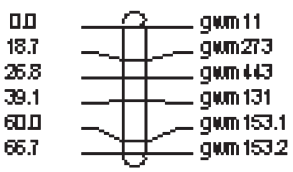

2B

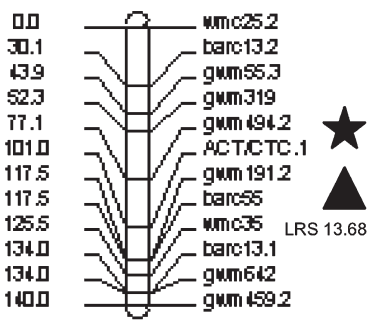

3日

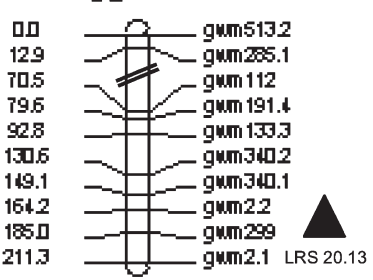

4B

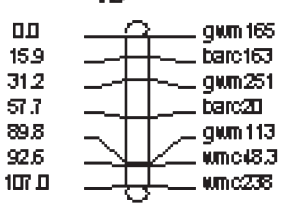

$6 \mathrm{~B}$

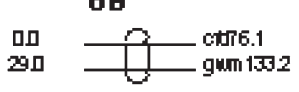

10

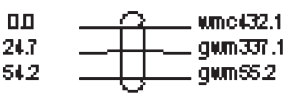

2D

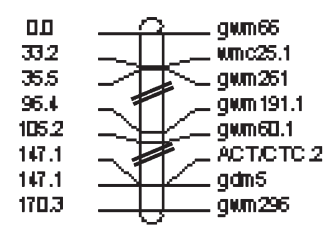

3D

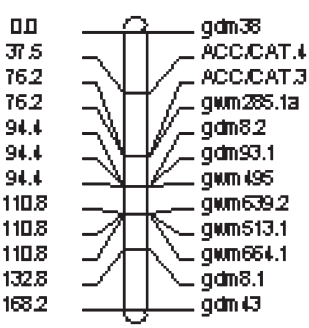

4D

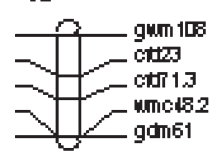

50

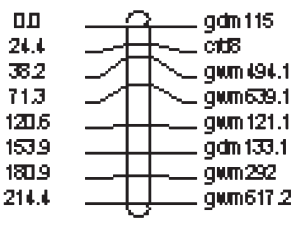

7 A

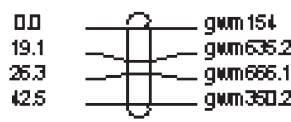

$7 \mathrm{~B}$

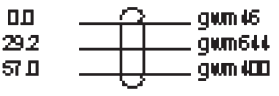

BD

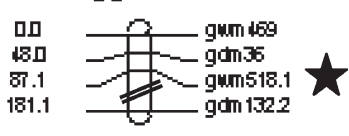

70

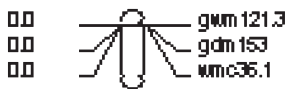

Fig. 2. AUS13124 $\times$ Janz map. The AUS13124 $\times$ Janz map consisted of 114 markers, arranged across 18 linkage groups. The total distance covered was $1987 \mathrm{cM}$, with an average intermarker spacing of $17 \mathrm{cM}$. Of the 3 previously reported QTLs for Pratylenchus thornei [ $\star$ ] (Zwart et al. 2005 , 2006) and P. neglectus [ $\$$ ] (Williams et al. 2002), only the 2B locus was detected in the AUS13124 $\times$ Janz population. An additional QTL for $P$. thornei resistance, which explained up to $24 \%$ of phenotypic variation, was also detected on chromosome $3 \mathrm{~B}$ [ $\mathbf{\Delta}$ ]. The maximum LRS value for the 2B locus was $13.68(P<0.05$ threshold $=10.06)$. Maximum LRS for the 3B locus was $20.13(P<0.05$ threshold $=13.24)$. 

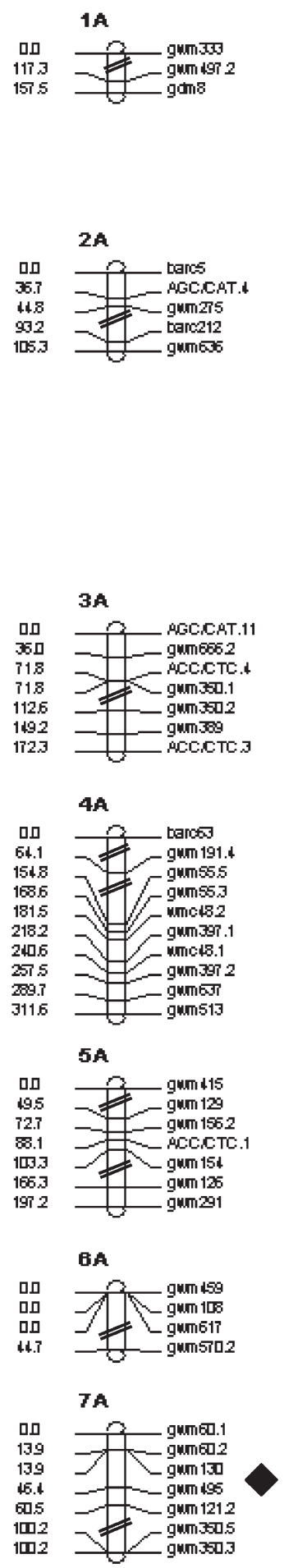

18

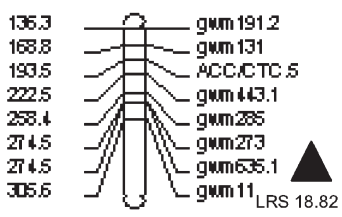

$2 \mathrm{~B}$

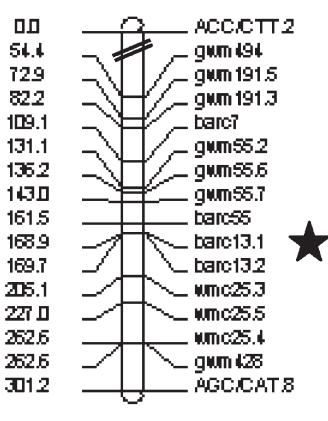

$3 \mathbf{B}$

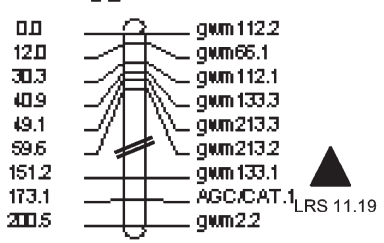

$4 \mathrm{~B}$
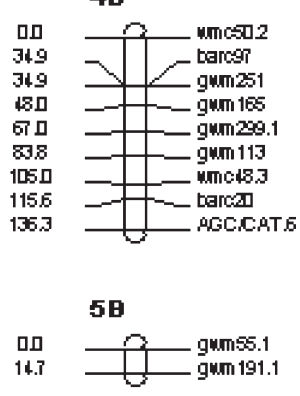

GB

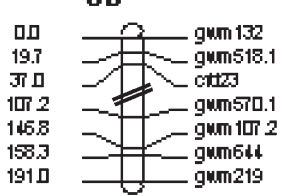

78

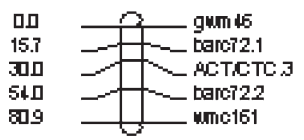

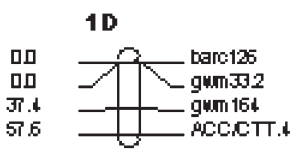
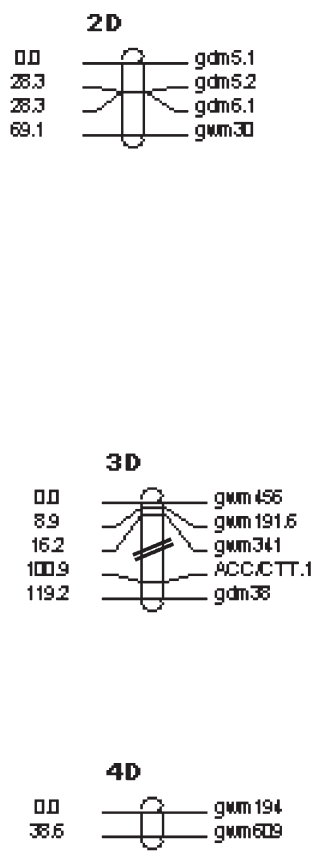

$5 D$

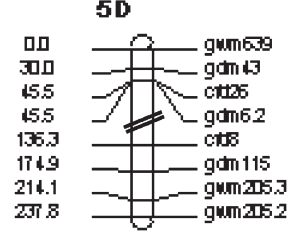

BD
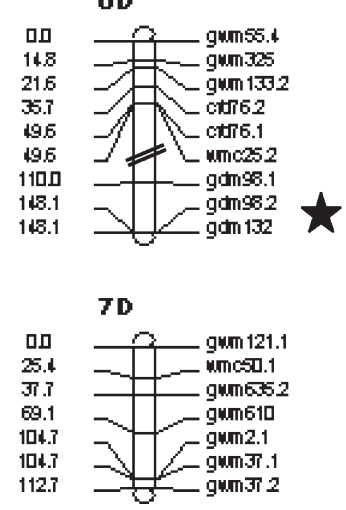

Fig. 3. AUS4926 $\times$ Janz map. The AUS4926 $\times$ Janz map consisted of 148 markers, arranged across 22 linkage groups. The total distance covered was $3230 \mathrm{cM}$, with an average intermarker spacing of $22 \mathrm{cM}$. In addition to the 3 previously reported QTLs for Pratylenchus thornei [ $\star$ ] (Zwart et al. 2005, 2006) and P. neglectus [ ] (Williams et al. 2002), additional QTLs for P. thornei resistance, explaining $21 \%$ and $12 \%$, respectively, of phenotypic variation, were also detected on chromosomes 1B and 3B $[\mathbf{\Delta}]$. The maximum LRS value for the 1B locus was $18.82(P<0.05$ threshold $=13.2)$. Maximum LRS for the 3B locus was $11.19(P<0.10$ threshold 9.8). 
$\left(\chi^{2}=9.48, \quad n=122\right), \quad$ gwm55.6 $\quad\left(\chi^{2}=6.42, \quad n=122\right)$, wmc25.4 $\left(\chi^{2}=18.58, n=124\right)$, AGC/CAT.11 $\left(\chi^{2}=6.45\right.$, $n=113), \quad$ gwm191.4 $\quad\left(\chi^{2}=75.54, \quad n=122\right), \quad$ gwm513 $\left(\chi^{2}=9.17, n=126\right)$, AGC/CAT.6 $\left(\chi^{2}=8.04, n=112\right)$, gwm415 $\left(\chi^{2}=13.5, \quad n=96\right), \quad \operatorname{gdm} 98.2 \quad\left(\chi^{2}=9.0\right.$, $n=81), \quad$ gwm $350.5 \quad\left(\chi^{2}=14.62, \quad n=115\right), \quad$ gwm121.1 $\left(\chi^{2}=12.57, \quad n=121\right), \quad \operatorname{wmc50.1} \quad\left(\chi^{2}=18.33, \quad n=83\right)$, gwm635.2 $\left(\chi^{2}=31.03, n=116\right)$, and gwm610 $\left(\chi^{2}=7.07\right.$, $n=105)$.

\section{Regression analysis}

Single marker regression resulted in the identification of 26 loci linked to RLN counts in the AUS13124 $\times$ Janz population (Table 1). Of these, 9 showed significant linkage $(P<0.05)$ in both 2001 and 2003 . These loci were located on chromosomes 2B, 2D, 3B, 6B, and 6D (Table 1) and individual marker genotypes explained $3-11 \%$ of phenotypic variation in 2001 and $10-23 \%$ in 2003.

In the AUS4926 $\times$ Janz population, single marker regression resulted in the identification of 26 loci linked to RLN counts (Table 2). Of these, 5 showed significant linkage $(P<0.05)$ in both 2001 and 2003. These loci were located on chromosomes 3B, 4A, 5B, 6D, and 7A (Table 2) and individual marker loci explained 5-23\% of phenotypic variation in 2001 and $3-25 \%$ in 2003.

\section{QTL analysis}

Significant QTL associations were detected on 3 chromosomes (Tables 3, 4). A resistance locus on chromosome 2B, detected only in the AUS13124 $\times$ Janz population (Tables 3, 4, Fig. 2), accounted for $6 \%$ of phenotypic variation in 2001 and $13 \%$ in 2003. A resistance locus on chromosome 3B (Tables 3, 4, Fig. 2) accounted for up to $12 \%$ of phenotypic variation in the AUS4926 $\times$ Janz (Table 4, Fig. 3) population in 2003 and $24 \%$ of phenotypic variation in AUS13124 $\times$ Janz (Table 3, Fig. 2). A third resistance locus on chromosome 6D (Zwart et al. 2005, 2006) did not surpass the significance threshold in either population (Tables 3, 4). A susceptibility QTL located on chromosome 1B in AUS4926 $\times$ Janz (Table 4, Fig. 3) explained $21 \%$ of phenotypic variation in 2003 (Table 4 , Fig. 3).

Results of QTL analysis were generally consistent with results of single marker regression, and markers that had shown significant linkage with phenotype in regression analysis flanked all QTLs that passed the significance

Table 1. Molecular markers linked to Pratylenchus thornei resistance in the AUS13124 x Janz population Individual markers showing significant association with phenotype in single factor regression analysis of the AUS13124 $\times$ Janz population. Map locations of linked markers (Chromosome), association with resistance (R) or susceptibility (S), and donor parent (Donor) are indicated in addition to likelihood ratio statistics (LRS), percentage of phenotypic variation explained by each marker genotype (\%Var), and exact $P$-values. Markers showing significant $(P<0.05)$ linkage in both years are shown in bold type

\begin{tabular}{|c|c|c|c|c|c|c|c|c|c|}
\hline \multirow[t]{2}{*}{ Chromosome } & \multirow[t]{2}{*}{ Marker } & \multirow[t]{2}{*}{$\mathrm{R} / \mathrm{S}$} & \multirow[t]{2}{*}{ Donor } & \multicolumn{3}{|c|}{2001} & \multicolumn{3}{|c|}{2003} \\
\hline & & & & LRS & $\% \operatorname{Var}$ & $P$ & LRS & $\% \operatorname{Var}$ & $P$ \\
\hline $1 \mathrm{~A}$ & gwm156 & $\mathrm{S}$ & Janz & 1.1 & 1 & 0.20342 & 4.1 & 10 & 0.04361 \\
\hline \multirow[t]{2}{*}{ 1B } & gwm11 & $\mathrm{S}$ & Janz & 1.0 & 1 & 0.32113 & 4.0 & 11 & 0.04604 \\
\hline & gwm443 & $\mathrm{S}$ & Janz & 4.3 & 3 & 0.03856 & 3.0 & 7 & 0.08545 \\
\hline $2 \mathrm{~A}$ & gdm6.1 & $\mathrm{S}$ & Janz & 4.7 & 4 & 0.02971 & 0.6 & 1 & 0.44851 \\
\hline \multirow[t]{5}{*}{ 2B } & wmc 25.2 & $\mathrm{R}$ & AUS13124 & 3.0 & 3 & 0.08505 & 7.8 & 18 & 0.00527 \\
\hline & barc13.2 & $\mathrm{R}$ & AUS13124 & 3.0 & 2 & 0.08130 & 5.1 & 12 & 0.02389 \\
\hline & gwm55.3 & $\mathrm{R}$ & AUS13124 & 3.7 & 3 & 0.05342 & 6.8 & 16 & 0.00899 \\
\hline & gwm494.2 & $\mathbf{R}$ & AUS13124 & 7.5 & 6 & 0.00600 & 10.3 & 23 & 0.00136 \\
\hline & gwm191.2 & $\mathbf{R}$ & AUS13124 & 6.6 & 5 & 0.01031 & 8.0 & 18 & 0.00476 \\
\hline \multirow[t]{3}{*}{$2 \mathrm{D}$} & gwm66 & $\mathrm{R}$ & AUS13124 & 5.0 & 5 & 0.02470 & 1.3 & 4 & 0.25788 \\
\hline & gwm191.1 & $\mathbf{R}$ & AUS13124 & 8.7 & 7 & 0.00323 & 4.2 & 10 & 0.04081 \\
\hline & gwm60.1 & $\mathrm{R}$ & AUS13124 & 9.8 & 7 & 0.00175 & 2.3 & 6 & 0.13214 \\
\hline \multirow[t]{4}{*}{ 3B } & gwm133.3 & $\mathrm{R}$ & Janz & 3.5 & 3 & 0.06088 & 6.6 & 15 & 0.01012 \\
\hline & gwm340.2 & $\mathbf{S}$ & AUS13124 & 5.5 & 4 & 0.01935 & 6.3 & 15 & 0.01227 \\
\hline & gwm2.2 & $\mathbf{S}$ & AUS13124 & 4.9 & 4 & 0.02646 & 7.5 & 17 & 0.00633 \\
\hline & gwm299 & $\mathbf{S}$ & AUS13124 & 4.3 & 3 & 0.03729 & 8.2 & 19 & 0.00417 \\
\hline \multirow[t]{2}{*}{$5 \mathrm{~A}$} & gwm497.3 & $\mathrm{R}$ & Janz & 1.7 & 1 & 0.19066 & 5.0 & 12 & 0.02530 \\
\hline & gwm126 & $\mathrm{R}$ & Janz & 2.3 & 3 & 0.13334 & 4.4 & 17 & 0.03679 \\
\hline \multirow[t]{2}{*}{$5 \mathrm{D}$} & gwm494.1 & $\mathrm{R}$ & AUS13124 & 4.9 & 4 & 0.02632 & 3.5 & 8 & 0.06267 \\
\hline & gwm617.2 & $\mathrm{R}$ & AUS13124 & 6.4 & 14 & 0.01171 & 1.3 & 10 & 0.25345 \\
\hline $6 \mathrm{~B}$ & cfd76.1 & $\mathbf{R}$ & AUS13124 & 7.0 & 6 & 0.00811 & 6.8 & 17 & 0.00909 \\
\hline \multirow[t]{3}{*}{$6 \mathrm{D}$} & gwm469 & $\mathrm{R}$ & AUS13124 & 10.9 & 9 & 0.00094 & 1.8 & 5 & 0.18287 \\
\hline & gwm518.1 & $\mathbf{R}$ & AUS13124 & 7.4 & 6 & 0.00658 & 5.9 & 14 & 0.01486 \\
\hline & gdm132.2 & $\mathbf{R}$ & AUS13124 & 11.9 & 11 & 0.00055 & 4.7 & 14 & 0.02978 \\
\hline $7 \mathrm{~A}$ & gwm154 & $\mathrm{R}$ & AUS13124 & 4.1 & 16 & 0.04292 & 0.1 & 1 & 0.76476 \\
\hline $7 \mathrm{~B}$ & gwm400 & $\mathrm{S}$ & Janz & 4.2 & 3 & 0.04097 & 2.0 & 5 & 0.15367 \\
\hline
\end{tabular}


Table 2. Molecular markers linked to Pratylenchus thornei resistance in the AUS4926 $\times$ Janz population

Individual markers showing significant association with phenotype in single factor regression analysis of the AUS4926 $\times$ Janz population. Map locations of linked markers (Chromosome), association with resistance (R) or susceptibility (S), and donor parent (Donor) are indicated in addition to likelihood ratio statistics (LRS), percentage of phenotypic variation explained by each marker genotype (\%Var), and exact $P$-values. Markers showing significant $(P<0.05)$ linkage in both years are shown in bold type

\begin{tabular}{|c|c|c|c|c|c|c|c|c|c|}
\hline \multirow[t]{2}{*}{ Chromosome } & \multirow[t]{2}{*}{ Marker } & \multirow[t]{2}{*}{$\mathrm{R} / \mathrm{S}$} & \multirow[t]{2}{*}{ Donor } & \multicolumn{3}{|c|}{2001} & \multicolumn{3}{|c|}{2003} \\
\hline & & & & LRS & $\% \operatorname{Var}$ & $P$ & LRS & $\%$ Var & $P$ \\
\hline $1 \mathrm{~A}$ & gwm333 & $\mathrm{R}$ & AUS4926 & 1.3 & 1 & 0.26247 & 4.7 & 12 & 0.03092 \\
\hline \multirow[t]{3}{*}{$1 \mathrm{~B}$} & gwm131 & $\mathrm{S}$ & Janz & 2.7 & 2 & 0.10241 & 5.1 & 13 & 0.02327 \\
\hline & gwm443 & S & Janz & 0.1 & 0 & 0.79411 & 5.6 & 13 & 0.01756 \\
\hline & gwm 273 & S & Janz & 1.3 & 1 & 0.24625 & 9.9 & 22 & 0.00170 \\
\hline \multirow[t]{2}{*}{$1 \mathrm{D}$} & gwm164 & S & Janz & 5.5 & 4 & 0.01904 & 1.1 & 3 & 0.28595 \\
\hline & ACC/CTT.4 & S & Janz & 7.1 & 7 & 0.00755 & 3.5 & 11 & 0.06303 \\
\hline \multirow[t]{3}{*}{$3 \mathrm{~B}$} & gwm112.2 & $\mathbf{R}$ & AUS4926 & 3.3 & 3 & 0.06918 & 4.7 & 15 & 0.03000 \\
\hline & gwm66 & $\mathrm{R}$ & AUS4926 & 2.9 & 2 & 0.08626 & 7.6 & 18 & 0.00573 \\
\hline & gwm133.3 & $\mathbf{R}$ & AUS4926 & 6.6 & 5 & 0.01038 & 4.6 & 11 & 0.03173 \\
\hline $4 \mathrm{~A}$ & barc63 & $\mathbf{R}$ & AUS4926 & 7.4 & 8 & 0.00666 & 6.8 & 25 & 0.00894 \\
\hline $5 B$ & gwm191.1 & $\mathbf{R}$ & Janz & 6.5 & 5 & 0.01090 & 8.9 & 22 & 0.00290 \\
\hline $5 \mathrm{D}$ & $\operatorname{gdm} 43$ & $\mathrm{R}$ & Janz & 4.6 & 5 & 0.03267 & 0.2 & 1 & 0.61758 \\
\hline $6 \mathrm{~A}$ & gwm459 & $\mathrm{R}$ & Janz & 6.2 & 5 & 0.01284 & 2.9 & 8 & 0.09131 \\
\hline $6 \mathrm{~B}$ & $\operatorname{cfd} 23$ & S & Janz & 0.6 & 0 & 0.45045 & 4.7 & 12 & 0.02971 \\
\hline $6 \mathrm{D}$ & $\operatorname{gdm} 132$ & $\mathbf{R}$ & AUS4926 & 11.5 & 12 & 0.00070 & 7.4 & 24 & 0.00636 \\
\hline $7 \mathrm{~A}$ & gwm350.3 & $\mathbf{R}$ & AUS4926 & 9.6 & 23 & 0.00195 & 3.7 & 3 & 0.05357 \\
\hline $7 \mathrm{~B}$ & barc 72.1 & S & Janz & 2.3 & 2 & 0.12757 & 3.9 & 13 & 0.04728 \\
\hline \multirow{3}{*}{$7 \mathrm{D}$} & gwm121.1 & $\mathrm{R}$ & Janz & 2.5 & 2 & 0.11327 & 6.0 & 15 & 0.01404 \\
\hline & wmc 50.1 & $\mathrm{R}$ & Janz & 0.0 & 0 & 0.88672 & 6.1 & 15 & 0.01343 \\
\hline & gwm635.2 & $\mathrm{R}$ & Janz & 0.9 & 1 & 0.33714 & 4.4 & 11 & 0.03567 \\
\hline
\end{tabular}

Table 3. Quantitative trait loci for Pratylenchus thornei resistance in AUS13124 x Janz population Quantitative trait loci detected via composite interval mapping in the AUS13124 $\times$ Janz population. Flanking markers are listed for each QTL, along with their map locations (Chromosome), chromosomal positions (Position), and inter-marker intervals (Interval). Maximum likelihood ratio statistics (LRS), percentage of phenotypic variation explained by the QTL $\left(R^{2}\right)$, and additive effects (Add.) are provided in alignment with the appropriate inter-marker interval. Threshold values for the LRS statistic (both $P<0.05$ and $P<0.10$ ), as determined by permutation testing, are provided for each chromosome. Note that in this population, only the $2 \mathrm{~B}$ and $3 \mathrm{~B}$ loci are significant. Data for chromosome $1 \mathrm{~B}$ are included for comparison with data from the AUS4926 population (Table 4), and data for the 6D locus are included for comparison with previous studies

\begin{tabular}{|c|c|c|c|c|c|c|c|c|c|c|c|c|c|}
\hline \multirow[t]{3}{*}{ Chromosome } & \multirow{3}{*}{ Position } & \multirow{3}{*}{$\begin{array}{l}\text { Flanking } \\
\text { markers }\end{array}$} & \multirow[t]{3}{*}{ Interval } & \multicolumn{5}{|c|}{2001} & \multicolumn{5}{|c|}{2003} \\
\hline & & & & \multicolumn{2}{|c|}{ Threshold } & \multirow[t]{2}{*}{ LRS } & \multirow[t]{2}{*}{$R^{2}$} & \multirow[t]{2}{*}{ Add. } & \multicolumn{2}{|c|}{ Threshold } & \multirow[t]{2}{*}{ LRS } & \multirow[t]{2}{*}{$R^{2}$} & \multirow[t]{2}{*}{ Add. } \\
\hline & & & & $P<0.05$ & $P<0.10$ & & & & $P<0.05$ & $P<0.10$ & & & \\
\hline \multirow[t]{3}{*}{$1 \mathrm{~B}$} & & & & 6.49 & 5.25 & & & & 8.34 & 7.01 & & & \\
\hline & 60 & gwm153.1 & & & & 3.28 & $6 \%$ & -0.858 & & & 3.64 & $3 \%$ & -0.052 \\
\hline & 67 & gwm 153.2 & 7 & & & & & & & & & & \\
\hline \multirow[t]{5}{*}{$2 \mathrm{~B}$} & & & & 9.49 & 6.99 & & & & 10.06 & 8.25 & & & \\
\hline & 52 & gwm319 & & & & & & & & & & & \\
\hline & 77 & gwm 494.2 & 25 & & & 9.47 & $6 \%$ & 1.449 & & & 13.68 & $13 \%$ & 0.1173 \\
\hline & 101 & ACT/CTC. 1 & 24 & & & & & & & & & & \\
\hline & 118 & gwm191.2 & 17 & & & & & & & & & & \\
\hline \multirow[t]{3}{*}{$3 \mathrm{~B}$} & & & & 8.30 & 7.20 & & & & 11.61 & 9.82 & & & \\
\hline & 93 & gwm133.3 & & & & 5.21 & $7 \%$ & -1.613 & & & 20.13 & $24 \%$ & -0.158 \\
\hline & 131 & gwm 340.2 & 38 & & & & & & & & & & \\
\hline \multirow[t]{5}{*}{$6 \mathrm{D}$} & & & & 16.20 & 13.54 & & & & 14.60 & 12.74 & & & \\
\hline & 0 & gwm469 & & & & & & & & & & & \\
\hline & 48 & $\operatorname{gdm} 36$ & 48 & & & 7.70 & $6 \%$ & 1.529 & & & 1.47 & $1 \%$ & -0.035 \\
\hline & 87 & gwm518 & 39 & & & & & & & & & & \\
\hline & 181 & $\operatorname{gdm} 132$ & 94 & & & 9.25 & $6 \%$ & 1.610 & & & 4.94 & $4 \%$ & -0.0698 \\
\hline
\end{tabular}

threshold. In keeping with the nomenclature put forwards by Williams et al. (2002) and Zwart et al. (2005), the novel susceptibility and resistance QTLs are designated QRlnt.cpi$1 B .1$ and QRlnt.cpi-3B.1, respectively.

\section{Discussion}

Zwart et al. (2004a) have previously demonstrated that root lesion nematode ( $P$. thornei) resistance is a polygenic, additive trait, meaning that marker-assisted selection and 
Table 4. Quantitative Trait Loci for Pratylenchus thornei Resistance in AUS4926 x Janz Population

Quantitative trait loci detected via composite interval mapping in the AUS4926 $\times$ Janz population. The 2B, 3B and 6D QTLs are resistance loci derived from AUS4926, while the 1B locus is a susceptibility locus derived from Janz. Flanking markers are listed for each QTL, along with their map locations (Chromosome), chromosomal positions (Position) and intermarker intervals (Interval). Maximum likelihood ratio statistics (LRS), percentage of phenotypic variation explained by the QTL $\left(R^{2}\right)$, and additive effects (Add.) are provided in alignment with the appropriate intermarker interval. Threshold values for the LRS statistic (both $P<0.05$ and $P<0.10$ ), as determined by permutation testing, are provided for each chromosome

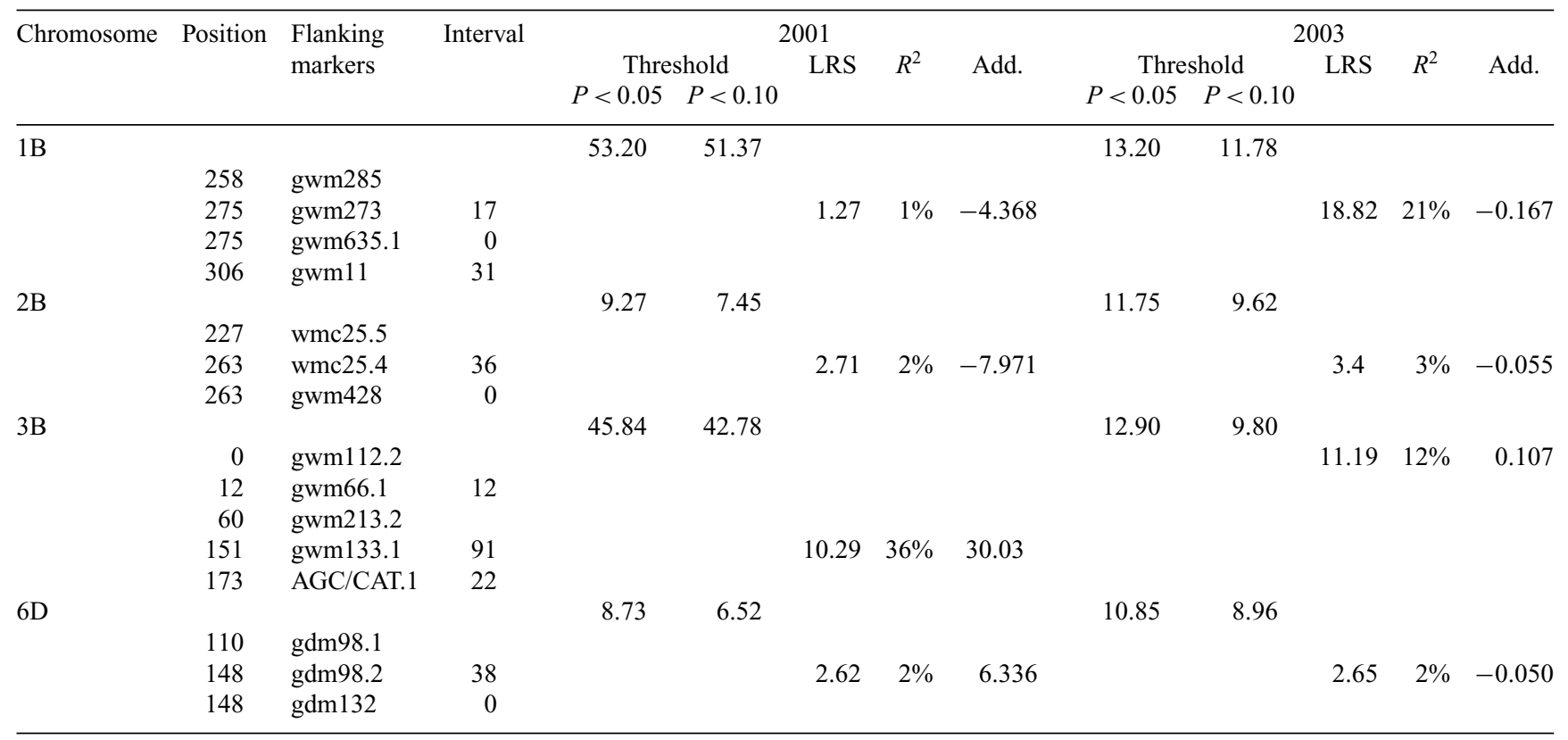

breeding programs offer significant opportunities for development of resistant cultivars. In this study, we have used 2 DH populations, derived from Middle-Eastern landraces crossed with the susceptible Australian cv. Janz, to confirm the presence of resistance loci on chromosomes $2 \mathrm{~B}, 6 \mathrm{D}$, and $7 \mathrm{~A}$, and to identify an additional resistance locus on chromosome $3 \mathrm{~B}$ and a susceptibility locus on chromosome 1B.

Although the 2003 phenotypic datasets for both populations were normally distributed, both populations showed non-normal phenotypic data in 2001 and parental means show substantial variation between years. The irregularities in phenotypic data reflect general difficulties associated with root lesion nematode resistance phenotyping and truncation of sampling in 2003 relative to 2001 (Proctor and Marks 1974; Barloy et al. 2000; Williams et al. 2002). Overall, Janz was consistently more susceptible than AUS13124 and AUS4926 (Fig. 1a,b) and previous studies have shown that QTL analysis is not universally compromised by non-normal distribution of phenotypic data (Kruglyak and Lander 1995); and in this case, replication of phenotypic measurements (with normal distribution in 2003), permutation testing of significance thresholds, and verification of results through QTL mapping and single marker regression have been used to counterbalance the variation between replicates.
Our results indicate that the previously detected QTLs on chromosomes $2 \mathrm{~B}, 6 \mathrm{D}$, and $7 \mathrm{~A}$ are less significant in the Middle-Eastern germplasm. The 2B locus surpasses the significance threshold in only one population (Table 3, AUS13124 $\times$ Janz), and the 6D and 7A QTLs are detected only in single marker regression (Tables 1,2 ). It is likely that chromosome 6D has simply not been mapped at sufficient density to detect the QRlnn.lrc-6D.1/QRlnt.lrc6D.1 QTL (Zwart et al. 2005) and the results of single marker analysis confirm that the 6D locus, which has also been detected in the Australian line GS50a (E. Lagudah, pers. comm.), is a broad-spectrum resistance locus. However, although GS50a has good resistance to $P$. thornei, it is very susceptible to P. neglectus (Zwart et al. 2004b), and Zwart etal. (2005) considered that there may be alternative alleles for these resistances at this $6 \mathrm{D}$ locus.

The 2B resistance locus also appears to have widespread presence, with at least one of the molecular markers linked to the QRlnn.lrc-2B.1/QRlnt.lrc-2B.1 QTL in the AUS13124 $\times$ Janz population among those reported by Zwart et al. (2005). This marker, wmc25.2, showed linkage with RLN resistance in both 2001 and 2003 (Table 1) and our results indicate that the markers gwm 494.2 and gwm191.2 should also be incorporated into screening for the chromosome 2B QTL. 
The utility of the 7A locus, reported from bulked segregant analysis of DH crosses of South Australian germplasm (Williams et al. 2002), may be less significant because, in our populations, the marker-trait association was detected only through single marker regression. However, for complex, quantitative traits, it is not unusual for the contributions of different loci to vary in magnitude both within and between populations/environments (Mackay 2001; Darvasi and Pisante-Shalom 2002) and our results suggest that there is significant potential for pyramiding of root lesion nematode resistance loci. In addition to confirming the presence of the $2 \mathrm{~B}, 6 \mathrm{D}$, and $7 \mathrm{~A}$ loci, we have identified a novel resistance locus on chromosome $3 \mathrm{~B}$ and a susceptibility locus on chromosome $1 \mathrm{~B}$. The susceptibility locus on chromosome 1B (AUS4926 $\times$ Janz) is flanked by the loci gwm285/gwm273 and gwm635.1 (Tables 2,4) and these markers could be used to screen for the locus in other polymorphic populations.

The QTL detected on chromosome 3B is contributed by the Janz allele in the AUS13124 $\times$ Janz cross, but by AUS4926 in the second population. It is possible that there are 2 separate QTLs located on this chromosome, but as linkage with the gwm 2.2 marker occurs in both the AUS13124 $\times$ Janz and AUS4926 $\times$ Janz populations, it is likely that there is only one QTL present. In the AUS13124 × Janz population, the resistance/susceptibility relationship is reversed and the most significantly linked markers are gwm 340.2 and gwm299, whereas in the AUS4926 $\times$ Janz population, the most significantly linked marker is gwm 133.3. Map locations for the common markers are similar in both populations, and further screening of resistance and susceptible germplasm may be required to identify polymorphic markers that can be used in widespread selection and breeding.

Combining results of single marker regression analysis and QTL mapping indicates that in the populations examined here, the loci on chromosomes 1B, 2B, 3B, $6 \mathrm{D}$, and $7 \mathrm{~A}$ make significant contributions to phenotypic variation, both independently and collectively. There is some variability in marker-trait relationships, which is likely to reflect several factors, including difficulties associated with obtaining quantitative data for pathogen/parasite resistance (Jung and Wyss 1999; Barloy et al. 2000) and complexity and/or variability in expression and regulation of polygenic traits (Mackay 2001). The percentage of phenotypic variation explained by marker genotypes also shows variation, but the significance of relationships between chromosome $1 \mathrm{~B}$ and $3 \mathrm{~B}$ markers and root lesion nematode resistance is consistent across populations/years/analytical approaches (single marker regression and QTL analysis), indicating that the development and implementation of marker-assisted selection has the potential to yield significant gains in breeding programs. Broad-scale screening (phenotyping and genotyping) of germplasm for the known resistance/susceptibility loci should assist in clarification of marker-trait relationships and facilitate pyramiding of resistance genes.

\section{Acknowledgments}

This work was funded by a research grant from the Australian Grains Research and Development Corporation, and was conducted as part of the Australian Winter Cereals Molecular Marker Program. The results reported in this study were generated as part of a collaborative research program designed to address issues specific to Australia's northern wheat-growing region, involving staff from CSIRO Plant Industry, The University of Southern Queensland, CIMMYT, and Queensland Department of Primary Industries. Within this program, R. Grams and R. Zwart, and M. Sutherland made contributions to this work. M. Miyagi assisted with phenotyping.

\section{References}

Barloy D, Lemoine J, Dredryver F, Jahier J (2000) Molecular markers linked to the Aegilops variabilis-derived root-knot nematode resistance gene Rkn-mnl in wheat. Plant Breeding 119, 169-172. doi: 10.1046/j.1439-0523.2000.00451.x

Berry DA (1987) Logarithmic transformations in ANOVA. Biometrics 43, 439-456.

Churchill GA, Doerge RW (1994) Empirical threshold values for quantitative trait mapping. Genetics 138, 963-971.

Darvasi A, Pisante-Shalom A (2002) Complexities in the genetic dissection of quantitative trait loci. Trends in Genetics 18, 489-491. doi: 10.1016/S0168-9525(02)02767-1

Dundas IS, Frappell DE, Crack DM, Fisher JM (2001) Deletion mapping of a nematode resistance gene on rye chromosome 6R in wheat. Crop Science 41, 1771-1778.

Gupta PK, Balyan HS, Edwards KJ, Isaac P, Korzun V, et al. (2002) Genetic mapping of 66 new microsatellite (SSR) loci in bread wheat. Theoretical and Applied Genetics 105, 413-422. doi: 10.1007/s00122-002-0865-9

Harker N, Rampling LR, Shariflou MR, Hayden MJ, Holton TA, Morell MK, Sharp PJ, Henry RJ, Edwards KJ (2001) Microsatellites as markers for Australian wheat improvement. Australian Journal of Agricultural Research 52, 1121-1130. doi: 10.1071/AR01025

Jung C, Wyss U (1999) New approaches to control plant parasitic nematodes. Applied Microbiology and Biotechnology 51, 439-446. doi: 10.1007/s002530051414

Kruglyak L, Lander ES (1995) A nonparametric approach for mapping quantitative trait loci. Genetics 139, 1421-1428.

Mackay TFC (2001) The genetic architecture of quantitative traits. Annual Review of Genetics 35, 303-339. doi: 10.1146/annurev. genet.35.102401.090633

Manly KF, Cudmore RH Jr, Meer JM (2001) Map Manager QTX, crossplatform software for genetic mapping. Mammalian Genome 12, 930-932. doi: 10.1007/s00335-001-1016-3

Nombela G, Romero MD (2001) Field response to Pratylenchus thornei of a wheat line with the CreAet gene for resistance to Heterodera avenae. European Journal of Plant Pathology 107, 749-755. doi: 10.1023/A:1011923400460

Pestsova E, Ganal MW, Röder MS (2000) Isolation and mapping of microsatellite markers specific for the D genome of bread wheat. Genome 43, 689-697. doi: 10.1139/gen-43-4-689 
Proctor JR, Marks CF (1974) The determination of normalising transformations for nematode count data from soil samples and of efficient sampling schemes. Nematologica 20, 395-406.

Röder MS, Korzun V, Gill B, Ganal MW (1998) The physical mapping of microsatellite markers in wheat. Genetics 41, 278-283.

Schmidt AL, Gale KR, Ellis MH, Giffard PM (2004) Sequence variation at a microsatellite locus (XGWM261) in hexaploid wheat (Triticum aestivum) varieties. Euphytica 135, 239-246. doi: 10.1023/B:EUPH.0000014874.85495.59

Seymour NP, Thompson JP (2001) New sources of resistances to rootlesion nematodes (Pratylenchus thornei) in wheat from the Middle East. In 'Proceedings of the 10th Assembly of the Wheat Breeding Society of Australia'. Mildura. pp. 56-59. (Wheat Breeding Society of Australia: Toowoomba, Qld)

Song QJ, Fickus EW, Cregan PB (2002) Characterization of trinucleotide SSR motifs in wheat. Theoretical and Applied Genetics 104, 286-293. doi: 10.1007/s001220100698

Taylor SP, Vanstone VA, Ware AH, Mackay AC, Szot D, Russ MH (1999) Measuring yield loss in cereals caused by root lesion nematodes (Pratylenchus neglectus and $P$. thornei) with and without nematicide. Australian Journal of Agricultural Research 50, 617-622.

Thompson JP (1990) Treatments to eliminate root lesion nematode (Pratylenchus thornei Sher and Allen) from a vertisol. Nematologica 36, 123-127.

Thompson JP, Brennan PS, Clewett TG, Sheedy JG, Seymour NP (1999) Progress in breeding wheat for tolerance and resistance to root-lesion nematodes (Pratylenchus thornei). Australasian Plant Pathology 28, $45-52$.

Thompson JP, Haak MI (1997) Resistance to root-lesion nematode (Pratylenchus thornei) in Aegilops tauschii Coss., the D-genome donor to wheat. Australian Journal of Agricultural Research 48, 553-559. doi: 10.1071/A96167

Vanstone VA, Rathjen AJ, Ware AH, Wheeler RD (1998) Relationships between root lesion nematodes (Pratylenchus neglectus and $P$. thornei) and performance of wheat varieties. Australian Journal of Experimental Agriculture 38, 181-188. doi: 10.1071/EA97109
Varshney RK, Kumar A, Balyan HS, Roy JK, Prasad M, Gupta PK (2000) Characterization of microsatellites and development of chromosome specific STMS markers in bread wheat. Plant Molecular Biology Reporter 18, 5-16.

Wang S, Basten CJ, Gaffney P, Zeng Z-B (2004) 'Windows QTL Cartographer Version 2.0'. Statistical Genetics. (North Carolina State University: NC)

Whitehead AG, Hemming JR (1965) A comparison of some quantitative methods of extracting small vermiform nematodes from soil. Annals of Applied Biology 55, 25-38.

Williams KJ, Taylor SP, Bogacki P, Pallotta M, Bariana HS, Wallwork H (2002) Mapping of the root lesion nematode (Pratylenchus neglectus) resistance gene Rlnn1 in wheat. Theoretical and Applied Genetics 104, 874-879. doi: 10.1007/s00122-001-0839-3

Zwart RS, Thompson JP, Godwin ID (2004a) Genetic analysis of resistance to root-lesion nematode (Pratylenchus thornei) in wheat. Plant Breeding 123, 209-212. doi: 10.1111/j.14390523.2004.00986.x

Zwart RS, Thompson JP, Godwin ID (2005) Identification of quantitative trait loci for resistance to two species of root-lesion nematode (Pratylenchus thornei and P. neglectus) in wheat. Australian Journal of Agricultural Research 56, 345-352. doi: 10.1071/AR04223

Zwart RS, Thompson JP, Sheedy JG, Nelson JC (2006) Mapping quantitative trait loci for resistance to Pratylenchus thornei from synthetic hexaploid wheat in the International Triticeae Mapping Initiative (ITMI) population. Australian Journal of Agricultural Research 57, (In press).

Zwart RS, Thompson JP, Williamson PM, Seymour NP (2004b) Elite sources of resistance in wheat to root-lesion nematodes (Pratylenchus thornei and P. neglectus) and yellow spot (Pyrenophora tritic-repentis. In 'Proceedings of the 3rd Australian Soiborne Diseases Symposium’. p. 20. (South Australian Research and Development Insititute: Adelaide, S. Aust.)

Manuscript received 17 January 2005, accepted 30 June 2005 